\title{
Hydrogen Engine and Numerical Temperature-Entropy Chart for Hydrogen/Air Cycle Analysis
}

\author{
Elsayed M. Marzouk, Hamza A. Ghulman \\ Mechanical Engineering Department, College of Engineering and Islamic Architecture, Umm Al-Qura University, \\ Makkah, KSA \\ Email: emmarzouk@yahoo.com
}

Received 18 June 2015; accepted 17 August 2015; published 20 August 2015

Copyright (C) 2015 by authors and Scientific Research Publishing Inc.

This work is licensed under the Creative Commons Attribution International License (CC BY).

http://creativecommons.org/licenses/by/4.0/

(c) (i) Open Access

\section{Abstract}

Fast depletion of fossil fuels with its resources already passed its mid depletion region and the pollution levels already reached unsafe levels which make it utmost necessity to search for alternative fuels to meet sustainable energy demand with minimum environmental impact. Among alternative fuels, hydrogen is considered as the near future, long term renewable, sustainable and non-polluting fuel. In the present paper, hydrogen fueled internal combustion engine fundamentals highlighted and presented relating to hydrogen combustion properties. A Mat lab programmed hydrogen temperature-entropy-energy chart is developed and presented for fresh charge and products of combustion at different excess air factors per mole combustion gases. The chart, then, used to represent a SI hydrogen-fueled fuel/air cycle analysis, which proved to be valuable design tool for engine sizing and for prediction of engine performance. Predictions carried out using the hydrogen F/A cycle analysis at different $\lambda$ show low brake specific fuel consumption and low volume specific power compared with conventional SI engine.

\section{Keywords}

Hydrogen Engine, $\mathrm{H}_{2}$-Combustion Properties, $\mathrm{H}_{2}$-Fueled SI Engine, Temperature-Entropy Chart, Fuel/Air Cycle Analysis

\section{Introduction}

Hydrocarbon fuels have long been played a primary role in propulsion and power generation. Increase in strin- 
gent regulations on environment from exhaust emissions and future predictions for depletion of world petroleum reserves give strong impetus for research in the areas of alternative fuels and novel propulsion engines. Various alternative fuels such as LPG (Liquefied Petroleum Gas), Alcohols (Methanol and Ethanol), NG (Natural Gas), Biodiesel and Bio gasoline, and $\mathrm{H}_{2}$ (Hydrogen) have been given as substitutes for conventional hydrocarbon to reduce exhaust emissions [1]. Report [1] also highlighted and presented the novel propulsion engine at present time. Among these alternative fuels, hydrogen is considered as the near future, the long term renewable, sustainable, recyclable and non-polluting fuel [2]. Hydrogen-fueled internal combustion engine (ICE) is considered as the bridging technology from gasoline and diesel engines into the fuel cell engines. Significance is being attached to hydrogen in view to its $\mathrm{CO}_{2}$ free combustion, its properties and due to the fact that it can be produced from various feed stocks including renewable energy sources [3]. Though nitrogen oxides $\left(\mathrm{NO}_{\mathrm{x}}\right)$ emissions are formed upon hydrogen combustion, it can be minimized to low concentrations compared with hydrocarbon fuels [4].

\section{Combustion Properties of Hydrogen}

The following are some important characteristics of hydrogen which affect the technical development of hydrogen internal combustion engines.

\subsection{Flammability Range}

Hydrogen has a wide flammability range (4.0\% - 75\% compared to $1.4 \%-7.6 \%$ by volume in air for gasoline). This is of utmost importance for safe handling of hydrogen. However, this leads to the suitability for use in lean burn mixture engine. Lean mixture allows for better complete combustion and better thermal efficiency i.e. better economy. This in turn permits for lower for lower maximum combustion temperature that leads to lower nitrogen oxides $\left(\mathrm{NO}_{\mathrm{x}}\right)[3][5]$.

\subsection{Quenching Distance}

Hydrogen has a small quenching distance of $0.6 \mathrm{~mm}$ compared to $2.0 \mathrm{~mm}$ for gasoline. This is the distance from the cylinder wall where flame front extinguishes. This means it is more difficult to extinguish the hydrogen flame and implies more susceptibility of the engine to backfire since the hydrogen-air mixture flame more easily passes through valves than the gasoline-air mixture flame [3] [6].

\subsection{Flame Speed}

Hydrogen burns with high flame front speed. This allows hydrogen engines to thermodynamically more closely approach the constant volume heat addition ideal cycle. This resemblance is adequate for stoichiometric mixture, when hydrogen engine runs lean to improve fuel economy and reduce nitrogen oxides, the flame speed slows down. However, it is still very much higher than the gasoline-air mixture flame speed [3] [6]. Flame speed and maximum combustion temperature are of prime concern for thermal efficiency and emissions.

\subsection{Auto-Ignition Temperature}

Self-ignition temperature of hydrogen is high as $585^{\circ} \mathrm{C}$. This makes it difficult to ignite the hydrogen-air mixture without an external ignition source. Table 1 shows this temperature compared to gasoline and diesel fuels. The table also summarizes the other important properties. The auto-ignition temperature is an important property in determining the maximum compression ratio (Higher Useful Compression Ratio) that an engine can operate at [7].

\subsection{Minimum Ignition Energy}

The minimum ignition energy required to ignite the fuel-air mixture by an ignition source such as a spark plug for hydrogen is about an order of magnitude lower than gasoline-air mixture i.e. $0.02 \mathrm{~mJ}$ compared to $0.24 \mathrm{~mJ}$ for gasoline. The low ignition energy means that hot gases and hot spots on cylinder serve as sources of ignition creating premature ignition and flashback [3] [6]. 
Table 1. Properties of hydrogen and conventional fuels.

\begin{tabular}{|c|c|c|c|c|}
\hline Sl. No. & Property & Hydrogen & Gasoline & Diesel \\
\hline 1 & Formula & $\mathrm{H}_{2}$ & $\mathrm{C}_{\mathrm{n}} \mathrm{H}_{1.8 \mathrm{n}}$ & $\mathrm{C}_{\mathrm{n}} \mathrm{H}_{1.8 \mathrm{n}}$ \\
\hline 2 & Auto-ignition temperature $\left({ }^{\circ} \mathrm{K}\right)$ & 858 & $530-730$ & 530 \\
\hline 3 & Minimum ignition energy (mJ) & 0.02 & 0.24 & --- \\
\hline 4 & Flammability limits (volume \% in air) & $4-75$ & $1.4-7.6$ & $0.7-5$ \\
\hline 5 & Stoichiometric air-fuel ratio on mass basis & 35 & 14.6 & 14.5 \\
\hline 6 & Limits of flammability (equivalence ratio $\varphi$ ) & $0.1-7.1$ & $0.7-3.8$ & --- \\
\hline 7 & Density $\left(1 \mathrm{bar}, 16^{\circ} \mathrm{C}\right)$ & 0.084 & 750 & 820 \\
\hline 8 & L. heating value (mJ/kg) & 120 & 43.9 & 42.5 \\
\hline 9 & Flame speed $(\mathrm{cm} / \mathrm{s})$ & $265-325$ & $37-43$ & 30 \\
\hline 10 & Quenching distance NTP air (cm) & $0-06$ & 0.2 & --- \\
\hline 11 & Diffusivity air $\left(\mathrm{cm}^{2} / \mathrm{s}\right)$ & 0.63 & 0.08 & --- \\
\hline 12 & Octane number & 130 & $80-92$ & 30 \\
\hline 13 & Cetane number & --- & $40-55$ & $13-17$ \\
\hline
\end{tabular}

\subsection{Stoichiometric Air-Fuel Ratio and Mixture Energy Content}

The stoichiometric combustion equation for hydrogen in air is:

$$
\mathrm{H}_{2}+1 / 2\left(\mathrm{O}_{2}+3.76 \mathrm{~N}_{2}\right) \rightarrow \mathrm{H}_{2}+1.88 \mathrm{~N}_{2}
$$

Stoichiometric air/fuel ratio is $=8 / 0.23=35 \mathrm{~kg}_{\text {air }} / \mathrm{kg}_{\mathrm{H}_{2}}$

The excess air factor

$$
\lambda=(A / F) / 35
$$

MOLS of air/MOL of hydrogen for complete combustion $=2.38$.

This corresponds to stoichiometric volume percent of hydrogen in air-fuel mixture $=29.5$.

For gasoline the volume percent of fuel in stoichiometric fuel-air mixture is only 1.76, with $(A / F)_{\mathrm{st}}=14.6$.

Despite the lower calorific value of hydrogen is $120 \mathrm{~mJ} / \mathrm{kg}$ compared to the gasoline as $44 \mathrm{~mJ} / \mathrm{kg}$, the energy content per $\mathrm{m}^{3}$ of gas fuel-air mixture under standard atmospheric conditions is lower [8]. Based on flammability range by volume in air, the flammability limits of hydrogen vary from equivalence ratio $\varphi$ from 0.1 to 7.1. This enables the engine to run well into the lean mixture and prompts ignition and hence higher thermal efficiency [9]. Table 1 compares the properties of hydrogen and gasoline and diesel fuels.

\subsection{Low Density}

Without significance compression or conversion to liquid hydrogen, a very large volume may be necessary to store enough hydrogen to provide adequate drive range. It also implies the fuel-air mixture has low energy per unit mixture volume which reduces the engine output for carburetor or inlet port fuel induction. Thus, when hydrogen engine run lean issues of inadequate power arise [3].

\subsection{Configurations of Hydrogen Induction in ICE}

In spark ignition engine, hydrogen can be used as fuel almost similar to SI gasoline engine. There are now many companies start marketing hydrogen ICE engine vehicles e.g. Ford and BMW [9]. The fuel induction modes are carburetion, inlet manifold and inlet port injection and direct cylinder injection [10] [11]. Hydrogen cannot be used as a sole fuel in CI engine due to the high self-ignition temperature of hydrogen. Hydrogen fueling of diesel engine must have spark plug in addition to hydrogen injector [12]. 


\section{Models for $\mathrm{H}_{2}$ Four Stroke Engine Cycle}

The flame speed of hydrogen-air mixture is very high so that the ideal theoretical reference cycle would be the constant volume heat addition cycle. Also, to prevent excessive temperature inside the engine cylinder, the excess air factor $\lambda$ must be higher than stoichiometric (preferable set to 1.5 - 2). The maximum end temperature Tgobtained upon combustion of $\mathrm{H}_{2}$-air mixture at constant volume, for fuel lower calorific value of $120 \mathrm{~mJ} / \mathrm{kg}$ is:

$$
\begin{gathered}
(F * \text { L.C.V. })+\left(F * C_{v a} * T_{A}\right)=(A+F) * C_{v g} * T_{g} \\
120000+35 \lambda * C_{v a} * T_{a}=(35 \lambda+1) * C_{v g} * T_{g}
\end{gathered}
$$

Taking $C_{v a}=0.718 \mathrm{~kJ} / \mathrm{kg}^{\circ} \mathrm{K}, C_{v g}=1.0 \mathrm{~kJ} / \mathrm{kg}^{\circ} \mathrm{K}$ is given in the following Table 2 .

\subsection{Ideal Gas Standard Cycle (Figure 1)}

The working fluid in this cycle is assumed as air with constant specific heats with no fuel combustion but with equivalent amount of heat transferred through the cylinder wall. The specific heat ratio is taken as 1.4 and the compression ratio is 8 . Assuming $T 1=400^{\circ} \mathrm{K}, P 1=1$ bar.

The indicated thermal efficiciencyand the indicated mean effective pressure are obtained from Equations (5) and (6) and results in Table 3.

$$
\begin{gathered}
\eta_{t h i}=1-\frac{1}{r^{\gamma-1}}=0.565, \\
\frac{i m e p}{p 1}=\frac{(C . V)}{(1+35 \lambda)(C v T 1)} * \frac{r}{r-1} * \frac{1}{\gamma-1} * \eta_{t h i} \\
b m e p=i m e p * \eta_{\text {mech }} .
\end{gathered}
$$

\subsection{Generation of Temperature-Entropy-Energy Chart for $\mathrm{H}_{2}$}

The equation for combustion of $\mathrm{H}_{2}$ with excess air factor $\lambda$ can be written as:

$$
\mathrm{H}_{2}+\frac{1}{2} \lambda\left(\mathrm{O}_{2}+3.76 \mathrm{~N}_{2}\right) \rightarrow \mathrm{H}_{2} \mathrm{O}+\frac{1}{2}(\lambda-1) \mathrm{O}_{2}+\frac{1}{2} \lambda * 3.76 \mathrm{~N}_{2}
$$

- Number of moles before combustion is given by:
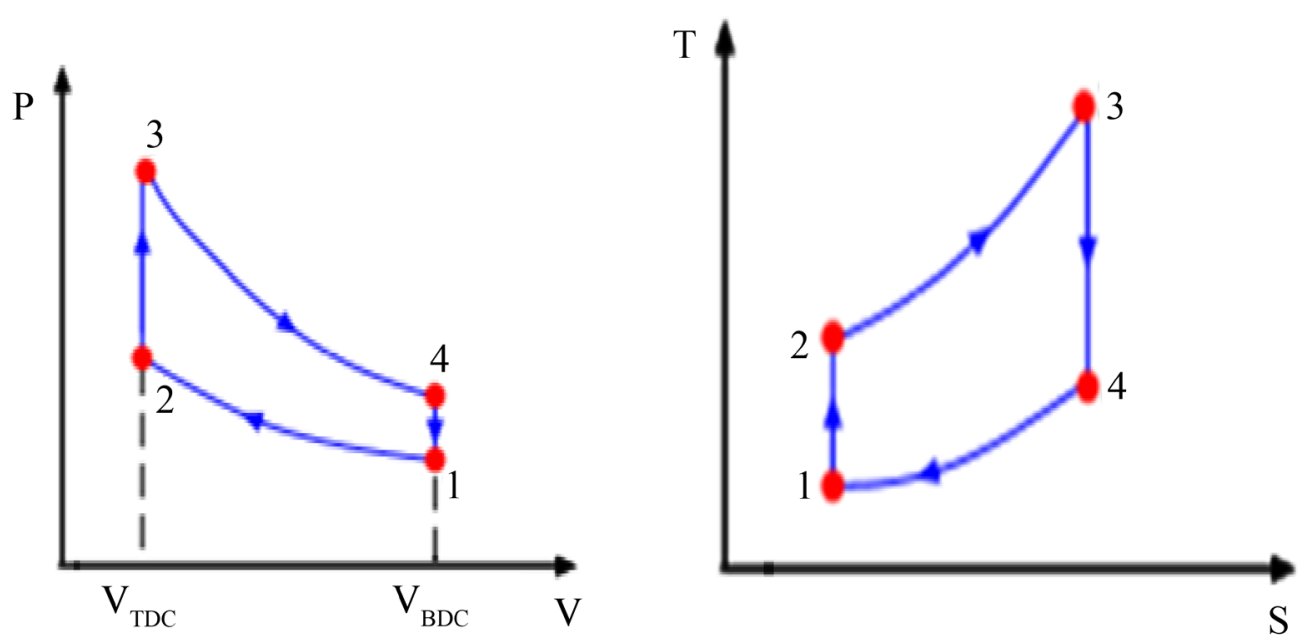

Figure 1. Gas standard cycle. 
Table 2. Maximum temperatures for different $\lambda$ values.

\begin{tabular}{ccc}
$\lambda$ & $\boldsymbol{A} / \boldsymbol{F}$ & $\boldsymbol{T}_{\boldsymbol{g}}{ }^{\circ} \mathbf{K}$ \\
\hline 1.0 & 35 & 3613 \\
1.5 & 52.5 & 2525 \\
2 & 70.0 & 1973 \\
2.5 & 87.5 & 1640 \\
\hline
\end{tabular}

Table 3. Variation of bmep \& imep for different $\lambda$.

\begin{tabular}{cccccccccccc}
\hline$\lambda$ & P1 & T1 & P2 & T2 & P3 & T3 & P4 & T4 & imep & bmep \\
\hline 1.0 & 1 & 400 & 18.4 & 919 & 3613 & 72.34 & 1573 & 3.93 & 18.74 \\
1.5 & 1 & 400 & 18.4 & 919 & 2525 & 50.55 & 1099 & 2.75 & 12.60 \\
2.0 & 1 & 400 & 18.4 & 919 & 1973 & 39.5 & 859 & 2.15 & 7.62 \\
\hline
\end{tabular}

$$
\begin{aligned}
n_{R} & =1+\frac{\lambda}{2}+3.76 \frac{\lambda}{2}=1+2.38 \lambda \\
& =0.5+1.19 \lambda \quad \text { per } \mathrm{Kg} \text { of Hydrogen }
\end{aligned}
$$

- Number of moles after combustion is given by:

$$
\begin{aligned}
n_{p} & =1+\frac{(\lambda-1)}{2}+3.76 \frac{\lambda}{2} \\
& =0.25+1.19 \lambda \quad \text { per Kg of Hydrogen }
\end{aligned}
$$

The calorific value is then L.C.V. = $120 \mathrm{MJ} / \mathrm{kg}$ hydrogen

$$
\frac{\mathrm{L} . \mathrm{C} . \mathrm{V} .}{n_{p}}=\frac{120}{(0.25+1.19 \lambda)} \mathrm{mJ} / \mathrm{mol}_{\mathrm{cg}}
$$

The following table shows (Table 4) $\frac{\text { L.C.V. }}{\mathrm{mol}_{\mathrm{cg}}}$ for different values of $(\lambda)$.

The products of combustion are shown in Table 5:

The molar specific heat of each constitutes of the combustion gases as function of temperature (T) [8]. This is based on polynomial curve fit to thermodynamic data assuming that the unburned mixture is frozen in composition and the burned mixture is in equillibrium. This is based on the equilibrium NASA program [12].

$$
\bar{C} p_{\mathrm{O}_{2}}=a_{\mathrm{O}_{2}, 1}+a_{\mathrm{O}_{2}, 2} T+a_{\mathrm{O}_{2}, 3} T^{2}+a_{\mathrm{O}_{2}, 4} T^{3}+a_{\mathrm{O}_{2}, 5} T^{4}
$$

Similar terms for $\bar{C} p_{\mathrm{H}_{2} \mathrm{O}}$, and $\bar{C} p_{\mathrm{N}_{2}}$ as function of temperature.

$$
\text { As: } \bar{C} p_{i}=\sum_{1}^{5} a_{i, 1} T^{(i-1)}
$$

These specific heats of products of combustion are also function of $(\lambda)$, the combustion gases molar specific heats at every temperature can be obtained in $\mathrm{KJ} / \mathrm{Kmol}_{\mathrm{cg}} .{ }^{\circ} \mathrm{K}$ as:

$$
\bar{C} p_{g}=\frac{1}{n c g} \bar{C} p_{\mathrm{H}_{2} \mathrm{O}}+\frac{(\lambda-1)}{2 * n c g} \bar{C} p_{\mathrm{O}_{2}}+\frac{\lambda * 3.76}{2 * n c g} \bar{C} p_{\mathrm{N}_{2}}
$$

If the reference state for internal energy $(\bar{u})$ and enthalpy $(\bar{h})$ is taken as $\bar{u}_{0}=0, \bar{h}_{0}$ at $T_{0}=0^{\circ} \mathrm{K}$

The internal energy and enthalpy can be obtained at different temperatures and different excess air factor $\lambda$ as:

$$
\bar{u}=\int_{0}^{T} \bar{C} v_{g} \mathrm{~d} T, \bar{h}=\int_{0}^{T} \bar{C} p_{g} \mathrm{~d} T
$$


Table 4. (L.C.V. per mol $_{\mathrm{cg}}$ ) for different $\lambda$ values.

\begin{tabular}{ccccc}
\hline$\lambda$ & 1 & 1.5 & 2 & 4 \\
\hline$\frac{\mathrm{moles}}{\mathrm{KgH_{2 }}}$ & 1.44 & 2.035 & 2.63 & 5.01 \\
$\frac{\text { L.C.V. }}{\mathrm{mol}_{c g}}$ & 83.33 & 58.99 & 45.63 & 23.95 \\
\hline
\end{tabular}

Table 5. Products of combustion of hydrogen.

\begin{tabular}{|c|c|c|c|c|c|c|}
\hline & M & Number of moles & $\lambda=1$ & $\lambda=1.5$ & $\lambda=2$ & $\lambda=4$ \\
\hline $\mathrm{O}_{2}$ & 32 & $\frac{\lambda-1}{2}$ & 0 & 0.25 & 0.5 & 1.5 \\
\hline $\mathrm{N}_{2}$ & 28 & $\frac{3.76 \lambda}{2}$ & 1.88 & 2.88 & 3.76 & 7.52 \\
\hline $\mathrm{H}_{2} \mathrm{O}$ & 18 & 1 & 1.0 & 1.0 & 1.0 & 1.0 \\
\hline \multicolumn{3}{|c|}{ Total number of moles } & 2.88 & 4.07 & 5.26 & 10.02 \\
\hline
\end{tabular}

The entropy at any given temperature and excess air factor $\lambda$ also can be obtained if the reference state point is taken as:

$$
\begin{aligned}
\bar{S}_{0}=0 \text { at } P_{0}=1 \mathrm{bar}, T_{0}=300^{\circ} \mathrm{K} \text { and } \bar{v}_{0} & =24.94 \mathrm{~m}^{3} / \mathrm{kmol}, \text { so that, } \\
\bar{S} p & =\int_{T_{0}}^{T} \bar{C} p_{g} \frac{\mathrm{d} T}{T}-\bar{R} \ln \frac{P}{P_{0}} \\
\bar{S} V & =\int_{T_{0}}^{T} \bar{C} v_{g} \frac{\mathrm{d} T}{T}-\bar{R} \ln \frac{\bar{v}}{\bar{v}_{0}}
\end{aligned}
$$

MATLAB is used in programmed mode to construct the temperature-entropy $(T-\bar{S})$ chart with constant pressure lines and constant specific volume lines, for different excess air factors $\lambda$, s. The temperature-internal energy lines $(T-\bar{u})$ and the temperature-enthalpy lines $(T-\bar{h})$ are also constructed on the chart for different excess air factors $\lambda$, s. All properties are given per mole combustion gases for reactants and products of combustion. The constructed temperature-entropy chart is shown in Figure 2 with some selected pressure and specific volumes lines and selected excess air factors.

\subsection{Fuel-Air Cycle Analysis for Hydrogen}

In this analysis, the actual fuel-air working fluid is used and the combustion is assumed to occur instantaneous at TDC. The change of specific heat of the reactants and products of combustion is taken into the analysis. The change of the number of molecules and dissociation effects are taken into account. However, as the mixture excess air factor is 1.5 or more, the effects of dissociation are minimal. As a demonstration to the numerical procedure, the hydrogen SI four stroke engine cycles is applied to the generated $(T-\bar{S})$ chart. The engine is four stroke, water cooled engine having compression ratio $r$ of 8 with hydrogen mixture excess air factor $\lambda$ of 1.5. The in cylinder gases condition at start of compression stroke is taken as $P_{1}=1 \mathrm{bar}$ and $T_{1}=400^{\circ} \mathrm{K}$. The isentropic compression from the known state point (1) to state point (2) with the known specific volume $\overline{v_{2}}$ from the specified engine compression ratio, is iterated using Equation (15) for an excess air factor $\lambda=\infty$ and initial guess of $T_{2}$. The temperature $T_{2}$ is incremented until $\bar{S}_{v 2}=\bar{S}_{v 1}+0.001$. At state (2) combustion carried out instantaneous and the working fluid changes into products of combustion at $\lambda=1.5$. The lower calorific value is $=$ $\frac{120000}{1.19 \lambda+0.25}=58968 \mathrm{~kJ} / \mathrm{kmol}_{\mathrm{cg}}$. Assuming the cooling water percent loss as $34 \%$, As distinct from gasoline or 
diesel fuel/air cycles , all heat of combustion is added at constant volume due excessively high flame speed.

The internal energy of combustion gases $\overline{u_{3}}$ is obtained from $q_{\text {effective }}=\overline{u_{3}}-\overline{u_{2}}$. The maximum cycle temperature is determined from $\overline{u_{3}}$ and the internal energy vector of combustion gases at different temperatures for $\lambda=1.5$ generated from Equation (13). For the constant specific volume line and known temperature determine the specific entropy per mole combustion gases at state (3). Isentropic expansion from state (3) to state (4) with known specific volume $\overline{v_{4}}$ is iterated using Equation (15) for excess air factor $\lambda=1.5$ and an initial guess lower than $T_{4}$ lower than $T_{3}$. With the temperature $T_{4}$ progressively decreased until $\bar{S}_{v 4}=\bar{S}_{v 3} \pm 0.001$. The properties of gases at state (4) is determined to obtain the exhaust gas loss, from which then, the indicated work done per cycle is determined. Engine sizing and performance parameters are predicted.

The hydrogen/air cycle numerical representation is shown in the Figure 2 for engine compression ratio of 8 and $\lambda=1.5$. The procedure is summerized as follows:

Point (1)

$P_{1}=1 \mathrm{bar}, T_{1}=400^{\circ} \mathrm{K}, \overline{v_{1}}=33.26 \mathrm{~m}^{3} / \mathrm{mol}_{\mathrm{cg}}$
$u_{1}=8572 \mathrm{~kJ} / \mathrm{mol}_{\mathrm{cg}}$

Point (2) Compression is isentroic from state (1) to (2) where $\overline{v_{2}}=4.16 \mathrm{~m}^{3} / \mathrm{mol}_{\mathrm{cg}}$

$P_{2}=13.75 \mathrm{bar}, T_{2}=767^{\circ} \mathrm{K}$, Then, $q_{\text {effective }}=\overrightarrow{u_{3}}-\overrightarrow{u_{2}}=38919 \mathrm{~kJ} / \mathrm{mol}_{\mathrm{cg}}$

$\underline{T_{3}}=1883^{\circ} \mathrm{K}$

$\underline{u_{4}}=35238 \mathrm{~kJ} / \mathrm{mol}_{\mathrm{cg}}$

Heat lost in exhaust $=35,238-8572=26,666 \mathrm{~kJ} / \mathrm{mol}_{\mathrm{cg}}$

IWD $=38,919-26,666=12,253 \mathrm{~kJ} / \mathrm{mol}_{\mathrm{cg}}$

The indicated thermal efficiency:

$\eta_{t h i}=\frac{12253}{58968}=20.8 \%, \quad \eta_{b t h}=18.1 \%$, the indicated mean effective pressure

imep $=\frac{W \cdot D / \text { cycle }}{\left(\overline{v_{1}}-\overline{v_{2}}\right)}=\frac{12253}{33.25}=421.1 \mathrm{kpa}$, brake mean effective pressure.

bmep $=421.1 * 0.87=366.33 \mathrm{kpa}$, where $\eta_{\text {mechanical }}=0.87$

brake specific fuel consumption $(\mathrm{bsfc})=\frac{3600}{0.181 \times 120000}=0.166 \mathrm{~kg} / \mathrm{kw} \cdot \mathrm{hr}$

If the engine develops $50 \mathrm{~kW} @ N=5000 \mathrm{rpm}, L / D=1 \mathrm{bmep}=\frac{P_{b}}{V_{s} *\left(\frac{N}{2}\right)}, V s=3.27$ liters with $L=D=$

$10.1 \mathrm{~cm} . P_{b} /$ liters $=15.3$ (which is low compared to modern gasoline engines).

The fuel/air cycle analysis of performance predictions compares very well with the actual engine cycles for petrol and diesel engine using hydrocarbon fuels [8]. The results obtained in the present work for hydrogen/air cycle analysis show a good estimate of engine sizing power developed and bsfc compared to that of actual engine. Also peak pressures and exhaust temperatures that affect engine structure and design can be closely predicted. The effect of many variables on hydrogen engine performance can also be understood.

For a certain engine configuration, CFD code Fluent which include the turbulence and detailed combustion processes that are modeled with sufficient generality to include delay period, chemical kinetics and flame propagation is then required. This simulation will give good understanding of in cylinder gas motion with detailed combustion process that are essential to improve performance and reduce emissions without sacrificing fuel economy and to study the effects of using different hydrogen fuel induction methods [13].

\section{Conclusion}

Chemical and combustion properties of hydrogen are highlighted and proved to be the near future and the long term sustainable non-polluting fuel. Numerical procedure of the hydrogen/air engine cycle analysis with the constructed temperature-entropy chart for the reactants and products of combustion at different excess air factors, carried out for engine design and engine performance prediction. The hydrogen fueled SI engine performance prediction at excess air factor of 1.5 shows very low bsfc and relatively low volume specific power compared with conventional modern gasoline engine. 


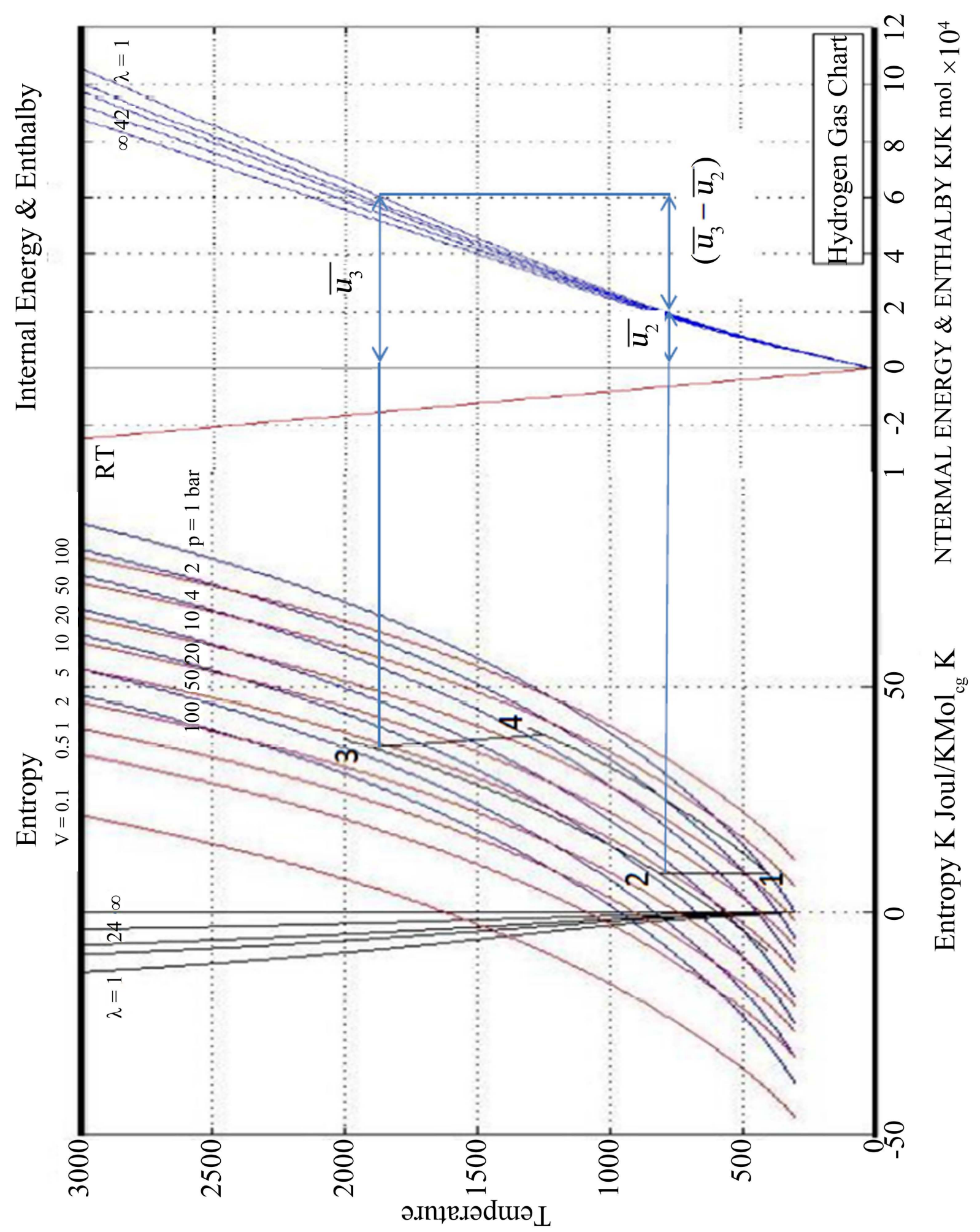

Figure 2. F/A cycle representation on temperature-entropy chart.

\section{References}

[1] Marzouk, E.M. (2015) Hydrogen Engine and Evaluation of $\mathrm{H}_{2}$ - Injection in SI Engine. Umm Al-Qura University, 
Report Department of Mechanical Engineering, Report No. 9, Makah, KSA.

[2] Antunes Gomes, M.J., Mikalsen, R. and Roskilly, A.P. (2008) An Investigation of Hydrogen Fuelled HCCI Engine Performance and Operation. International Journal of Hydrogen Energy, 33, 5823-5828. http://dx.doi.org/10.1016/j.ijhydene.2008.07.121

[3] Gillingham, K. (2007) Hydrogen Internal Combustion Engine Vehicles: A Prudent Intermediate Step or Step in the Wrong Direction. Department of Management and Engineering, Global Climate and Energy Project, Precourt Institute for Energy Efficiency, Stanford University.

[4] Saravanan, N., Najarajan, G., Sanjay, G. and Dhanassekaran, C. (2008) Combustion Analysis of a DI Diesel Engine with Hydrogen in Dual Fuel Mode. Fuel, 87, 3591-3599. http://dx.doi.org/10.1016/j.fuel.2008.07.011

[5] Ciniviz, M. and Kose, H. (2012) Hydrogen Use in Internal Combustion Engine: A Review. International Journal of Automotive Engineering and Technologies, 1, 1-15.

[6] Wahab, A. and Aswad, M. (2009) Addition of $\mathrm{H}_{2}$ to Gasoline Fuelled 4-Stroke SI Engine Using 1-Dimensional Analysis. Faculty of Mechanical Engineering, University of Malaysia Pahang, 1-68.

[7] Gupta, B.R. (2008) Hydrogen Fuel Production, Transport and Storage. CRC Press, Boca Raton, 1-603.

[8] Heywood, J.B. (1988) Internal Combustion Engine Fundamentals. McGraw-Hill Co., New York

[9] White, M.C. and Lutz, E.A. (2006) The Hydrogen Fuelled ICE: A Technical Review. International Journal of Hydrogen Energy, 31, 1292-1305. http://dx.doi.org/10.1016/j.ijhydene.2005.12.001

[10] Saravanan, N., Najarajan, G., Sanjay, G. and Dhanassekaran, C. (2007) Experimental Investigation of Hydrogen Port Fuel Injection in DI Diesel Engine. International Journal of Hydrogen Energy, 32, 4071-4080. http://dx.doi.org/10.1016/j.ijhydene.2007.03.036

[11] Das, M.L. (2002) Hydrogen Engine: Research and Development (R\&D) Programmers in Indian Institute of Technology, Delhi. International Journal of Hydrogen Energy, 27, 953-965. http://dx.doi.org/10.1016/S0360-3199(01)00178-1

[12] Svehla, R.A. and McBride, B.J. (1973) Fortran VI Computer Program for Calculation of Thermodynamic and Transport Properties of Complex Chemical Systems. NASA Technical Report TND-7056.

[13] Belal, T.M., Marzouk, E.M. and Osman M.N. (2013) Investigating Diesel Engine Performance and Emissions Using CFD. Journal of Energy and Power Engineering, 5, 171-180. http://dx.doi.org/10.4236/epe.2013.52017

\section{Nomenclature}

$a_{i, 1,2,3, \cdots, 5}$ : Polynomial coefficients for i-gas constituents.

A: Fuel flow rate $(\mathrm{kg} / \mathrm{hr})$.

$\bar{C} p_{i}, \bar{C} p_{c g}, \bar{C} p_{a}$ : Molar specific heat at constant pressure of i-gas constituents, combustion gases and air $\left(\mathrm{kJ} / \mathrm{mol} .{ }^{\circ} \mathrm{K}\right)$.

$\bar{C} v_{i}, \bar{C} v_{c q}, \bar{C} v_{a}$ : Molar specific heat at constant pressure of i-gas constituents, combustion gases and air $\left(\mathrm{kJ} / \mathrm{mol} \cdot{ }^{\circ} \mathrm{K}\right)$.

$D$ : Cylinder bore $(\mathrm{cm})$.

$F$ : Fuel flow rate (kg/hr).

$(A / F)$ : Mass air-fuel ratio.

$\bar{h}$ : Molar specific enthalpy $\left(\mathrm{kJ} / \mathrm{mol} \cdot{ }^{\circ} \mathrm{K}\right)$.

$L$ : Piston stroke (cm).

L.C.V.: Lower calorific value (kJ/kg).

$\mathrm{N}$ : Engine rotation speed (rpm).

$P$ : Absolute pressure (bar, $\mathrm{kPa}$ ).

$\bar{R}$ Universal gas constant $\left(8.314 \mathrm{~kJ} / \mathrm{mol} \cdot{ }^{\circ} \mathrm{K}\right)$.

$\bar{S}$ Molar specific entropy $\left(\mathrm{kJ} / \mathrm{mol} \cdot{ }^{\circ} \mathrm{K}\right)$.

$T$ : Absolute temperature $\left({ }^{\circ} \mathrm{K}\right)$.

$\bar{u}$ : Molar specific internal energy $\left(\mathrm{kJ} / \mathrm{mol} \cdot{ }^{\circ} \mathrm{K}\right)$.

$\bar{v}$ : Molar specific volume $\left(\mathrm{m}^{3} / \mathrm{mol}\right)$.

$\gamma$ : Specific heat ratio.

$\lambda$ : Excess air factor. 